\title{
SPEEDY babies: A putative new behavioral syndrome of unbalanced motor-speech development
}

\author{
Marja-Leena Haapanen' \\ Tuomo Aro' \\ Elina Isotalo ${ }^{2}$ \\ 'Deparment of Otorhinolaryngology, \\ Phoniatric Division, Helsinki \\ University Central Hospital, Helsinki, \\ Finland; ${ }^{2}$ Department of Neurology, \\ Peijas Hospital, Helsinki University \\ Central Hospital, Helsinki, Finland
}

\begin{abstract}
Even though difficulties in motor development in children with speech and language disorders are widely known, hardly any attention is paid to the association between atypically rapidly occurring unassisted walking and delayed speech development. The four children described here presented with a developmental behavioral triad: 1) atypically speedy motor development, 2) impaired expressive speech, and 3) tongue carriage dysfunction resulting in related misarticulations. Those characteristics might be phenotypically or genetically clustered. These children didn't have impaired cognition, neurological or mental disease, defective sense organs, craniofacial dysmorphology or susceptibility to upper respiratory infections, particularly recurrent otitis media. Attention should be paid on discordant and unbalanced achievement of developmental milestones. Present children are termed SPEEDY babies, where SPEEDY refers to rapid independent walking, SPEE and DY to dyspractic or dysfunctional speech development and lingual dysfunction resulting in linguoalveolar misarticulations. SPEEDY babies require health care that recognizes and respects their motor skills and supports their needs for motor activities and on the other hand include treatment for impaired speech. The parents may need advice and support with these children.
\end{abstract}

Keywords: speedy walking, speech disorder, misarticulations

\section{Introduction}

The children with idiopathic speech and language disorders are very heterogeneous by phenotype. The diagnosis of specific language impairment (SLI) is generally made by applying exclusion and inclusion criteria according to ICD 10 (1992). SLI is diagnosed, if the speech language development is significantly delayed, deviated or unclear and if the problem does not result from defective sense organs, any known neurological or neuropsychiatric disease, anomaly of oral apparatus or mental retardation (ICD 10 1992; Barry et al 2007). Shriberg and colleagues (2005) have examined diagnostic and phenotype markers for genetically transmitted speech delay. Considering the diagnostics, it is problematic that the phenotype changes with age. It is also difficult to evaluate the effect of recurrent early middle ear infections, particularly those with effusion, on speech and language development. It is generally thought that lengthened periods of otitis media with effusion impair acoustic-phonetic perception and persistent brain imprinting of speech sounds (Ptok and Eysholdt 2005). It is difficult to assess the prevalence and incidence of hereditary speech-language disorders because of the lack of clear criteria. The prevalence of familiar SLI is reported to be about 20\%-80\% in speech disordered children (Bishop and Edmundson 1986; Tallal et al 1989; Barry et al 2007). In typically developing children the respective estimation has been about 3\%-8\% (Bishop and Edmundson 1986; Tomblin et al 1997; Barry et al 2007). 
The suggestions of causes resulting in idiopathic speech-language disorders have varied during decades and affected the terminology and diagnostic criteria. No particular characteristics are attributed to any type of developmental speech and language disorders. Speech sound errors are common in all developmental speech and language disorders. Consistent articulation errors have been thought to originate from speech motor problems, whereas the label dysphonology has been attached to variable and unstable speech sound errors with no detectable physiologic or physical association. It has been argued that motor impairment cannot explain that a child is capable of producing a specific sound in one condition, but not in another. The inconsistency of speech sound errors has been taken as a linguistic disorder and a deficiency to use the sounds as a part of the language system (Gibbon 1999).

Because of the difficulty in recognizing the pathophysiology of the speech sound errors the term articulation/phonology disorder (APD) has been used. The omissions and substitutions of speech sounds have been suggested to represent phonological, ie, linguistic, disorders, while distortions indicate articulatory problems, ie, consistent dysfunction of articulating speech organs. These errors probably origin from undifferentiated lingual gestures, and thus reflect delayed or deviant control of functionally independent regions of the tongue. The lack of differentiation of articulators has been documented by electropalatography (Gibbon 1999). The lack of differentiation of the tongue tip and blade from the movements of posterior part of the tongue, as well as the difficulty in controlling the lateral parts of the tongue in sagittal groove formation, is typical in APD. APD children also tend to lift the posterior part of the tongue, when only anterior lift is required. Undifferentiated tongue movement reflects insufficient spatial acuity of the articulators that is typical in immature articulation. However, the motor variability in producing speech sounds may also result in linguistic impairment in terms of phonological inconsistency of the speech sound system of the language (Gibbon 1999). Considering developmental speech sound errors the term speech sound disorder (SSD) is currently preferred because this fairly common developmental disorder may have antecedents in both articulatory (sensorimotor) and phonological (cognitive-linguistic) domains (Lewis et al 2006; McGrath et al 2007). It is considered to be clinically useful to subtype the children with SSD into those that present with concomitant language disorder and to those without it (Lewis et al 2006).

The phonetico-phonological symptoms of APD and SSD share common speech characteristics with developmental verbal dyspraxia (DVD), childhood apraxia of speech (CAS), or developmental apraxia of speech (DAS). DAS and CAS have been described as disorders of speech motor programming and control. In them, the behavioral characteristics are numerous, including inconsistent speech sound errors and dysprosody (Forrest 2003; Nijland et al 2003; Jacks et al 2006). The later developing consonants (eg, /1/,/r/, /s/) are typically omitted or substituted by early developing ones. The initial and final consonants are often omitted, the overall consonant accuracy is low and the production of consonant clusters and complex mono- and polysyllables is typically difficult (Jacks et al 2006). The vowels may also be distorted, but the distortion is not always eliminated by advancing age (Davis et al 2005). Children with CAS (DAS/DVD) often present with severe and long lasting unintelligibility of speech, and the treatment so far lacks generally accepted effective methods (Davis et al 1998; Jacks et al 2006).

In summary, the developmental disorders APD, SSD, DVD, CAS, and DAS share common characteristics and the terms seem to be used somewhat synonymously (cf. Gibbon 1999; Forrest 2003; Nijland et al 2003; Jacks et al 2006; McGrath et al 2007). APD, SSD, DVD, CAS, and DAS are idiopathic expressive speech disorders that may be included in developmental language impairment (DLI) or specific language impairment (SLI).

Even though there is so far no consensus on the diagnostic inclusion or exclusion criteria and definition of DVD (Forrest 2003), a consensus has been obtained about the definition of general developmental dyspraxia (Sanger et al 2006). It is typical that the child has not yet achieved the skills to perform complex motor functions (in the absence of muscular weakness, involuntary muscular movements, or deficient selective control of muscular functions or ataxic disability to activate correct motor patterns) appropriate for age (Sanger et al 2006). This definition fits also well in DVD, which may be taken as narrow band disorder among developmental dyspraxias.

Disorders of motor development associated withDLI and SLI are common, widely recognized and reported (Bishop et al 1987; Robinson 1991; Rintala et al 1998; Hill 1998; Webster et al 2006). Motor problems are found to be common also in association with reading disability, even in $60 \%$ of cases (Kaplan et al 1998; Viholainen et al 2006).

It is generally thought that the children start walking without support at the average age of 12 months. According to the WHO multicenter study (2006), 50\% of the children have started to walk unassisted by the age of 12 months, 
about $25 \%$ by the age of 11 months, and $3 \%-10 \%$ by the age of 9-10 months. Very little attention, if at all, has been paid on speedy motor development in association with speech-language disorders. Even though speedy walking babies are less common in general population, they seem to be common among speech disordered children (Haapanen 2007). According to clinical observations, early walking seems to be familial also among those speech-language disordered children, particularly in children with expressive disorders that have started walking at typical age.

Haapanen (2007) has described a case series of 10 children with a particular developmental behavioral triad. They have unbalanced psychomotor development. The children have started to walk unassisted earlier than typical (at the latest by the age of 11 months), and they experience with expressive speech disorders resembling DAS and tongue movement dysfunction (lingual dysfunction with undifferentiated lingual movements resulting in dentoalveolar (ie, linguoalveolar) sound disorder. To name and describe them shortly, these children are here called SPEEDY babies ("Vauhtiveikot" in Finnish; Haapanen 2007) with SPEE referring to speech and DY to developmental dyspraxia or speech-language disorder such as developmental dysphasia, and dysfunction of the tongue.

The aim of the present case series that describes four children with unbalanced psychomotor development (SPEEDY babies) is to draw attention to children who walk early and have speech-language disorders, so that professionals may recognize the problem without delay. The coexistence of particular psychomotor characteristics is discussed in terms of interpreting them as a syndrome. In addition, a rough preliminary analysis of relevant demographic and clinical data in a series of 60 consecutive cases was carried out in order to make a preliminary estimation of the frequency of early independent walkers among speech disordered children and to explore the distribution of the age at unassisted walking between two diagnostic groups, ie, children with mainly expressive and mainly receptive verbal problems.

\section{Methods}

The demographic and clinical data of four cases are described. The children were referred to special medical consultation because of unclear speech, which caused social or emotional problems. All these four children were followed up and evaluated by a speech therapist several times each. The speech-language disorder was diagnosed on the basis of multidisciplinary evaluations, which included clinical examination performed by the medical speech pathologist and also individually administered, normative, and/or orienting tests and series of tasks that were performed by the speech therapist and the neuropsychologist.

Also, a series of 60 consecutive cases was preliminary examined. The data gathered included the diagnostic type of speech-language disorder (ie, whether mainly expressive vs receptive), the age of the occurrence of walking without support and the familial occurrence of speedy walking and speech/language/reading disabilities. The children with intelligence deficiency, abnormality of orofacial structures (except a minimal and nonsignificantly tongue tie, ie, short lingual frenulum), sense organ deficiency, psychiatric diagnosis or any recognizable neurological disease were excluded, as were also the children with a mother tongue some other than Finnish, or with the age of more than 6 years. The data were analyzed by Mann-Whitney U-test and Fisher's exact test.

\section{Case I}

A physically healthy male child was born after normal pregnancy and delivery. No sucking problems or dysphagia were ever reported. According to the parents' reports and the carefully made baby clinic registrations, he had begun to walk without support at the age of 10 months, he had about five verbal symbols by the age of 15-18 months, and he spoke short sentences by the age of $2-2.5$ years. Although the first words occurred at a normal age, his active vocabulary grew up slowly. Expressive speech remained limited even after the sentences occurred. The child was further referred to medical speech pathologist, ie, phoniatrician, at the age of 6 years for diagnosis and a comprehensive treatment plan.

Speech therapeutic intervention had been started at the age of 3 years because of unclear speech. Speech and language development was then assessed during 16 sessions by the speech therapist. The child presented with unintelligible words, sound substitutions, assimilations and other articulatory/phonological disorders typical of verbal dyspraxia. When re-evaluated and tested at the age of 6 years, he performed within mean age level in the Reynell speech comprehension test (Finnish version; Kortesmaa et al 2001), but achieved results that were slightly below mean age level in a Finnish normative sentence comprehension test (Korpilahti 1996). Narrating was difficult.

Psychological evaluations carried out at the age of 6 years were based on WPPSI-R (1995), the sentence and functional order comprehension items of the NEPSY test (Korkman et al 1997), RO (Rorschach test 1948), free play observation and as well a parent questionnaire and kindergarten report analysis. He was found normal by total cognitive development. 
He performed better in the performance items than in the language ones, albeit no significant discrepancy between them was found. General knowledge was good and general comprehension and mathematics were age-appropriate. He had strong visual, visual motor, and visuospatial skills. He expressed innovative ideas in some problem solving situations. He had some conceptual difficulties, particularly related to time, and some naming difficulty, albeit on the other hand he could describe some concepts better than what was typical for a child at his age. Auditive short term memory assessed by sentence repetition test was age-appropriate. His attention tended to impair slightly in complicated tasks.

By 6 years of age, his spontaneous speech was still unclear and he presented with some unintelligible words. Accuracy of articulation in free sentence level speech was decreased. No labial or velopharyngeal dysfunction was detected. However, he had lingual dysfunction. Many consonants were substituted by a sound auditively resembling a velar plosive $/ \mathrm{k} /$. He was still actively using the posterior part of the tongue in articulation. He also tended to speak with tongue tip and blade fixed to the bottom of the mouth. The mode of speaking resembled functional ankyloglossia resulting in alveolar sound distortions. However, initial consonant deletions, consistent substitutions, omissions or reversals were no more detected, except some consonant cluster assimilations. Yet, inconsistent sound substitutions and reversals typical of verbal dyspraxia were observed in semi sense sentences and nonsense word repetition tasks (such as PA-TA-KA), implicating the presence of latent dyspraxia. The nonverbal tongue movements were considerable slow and groping, but he was able to protrude the tongue out of the mouth, and bend it on the upper lip. The tongue was morphologically normal.

The child was found active and skilled in rough motor functions such as running, climbing, bicycling, and swimming. In kindergarten he was found impulsive and not very concentrated on issues that he was not interested in. But, no attentional problems were registered in association with issues and activities that he was interested in. According to kindergarten reports he was active, helpful, talkative, but he experienced some social problems with verbal communication because of unclear speech. Concentration in a big group was somewhat difficult. No suspicion of attention-deficit hyperactivity disorder (ADHD) was ever roused even though the child was lively.

The child had had only one middle ear infection so far, and no allergies were recognized. Hearing was normal, as tested by audiogram at the age of 6 years. His younger sister had begun to walk without support at the age of 9 months. The mother had begun to walk without support before 12 months of age. The parents had not suffered from speech, reading, or other learning disabilities.

For rehabilitative purposes, the child was recommended to be supported by parents and kindergarten stuff in social interaction and concentration. The speech therapist set the targets of individual intervention to improve abstract and basic concepts, as well as the clarity of the speech. The possibility of dyslexia could not be ruled out, and therefore the school stuff was recommended to organize the possibility of pedagogic rehabilitation by special teacher before hand. The follow up examinations of the child's development were scheduled to communal basic health care.

\section{Case 2}

A physically healthy male child was born after normal pregnancy and delivery. According to parents' report and health care registrations he begun to walk without support at the age of 7 months, but spoke the first words not earlier than by the age of 2.5 years. The first sentences consisting of two words occurred at the age of 3 years.

At the age of 5 years, the boy was referred to a local health care speech therapist because of unclear speech. He received 10 assessment and intervention sessions by the therapist that found the child talkative, yet presenting with the short sentences and inaccurate narrating. The speech and language were disordered by dysphonology and dysgrammatism. He also had word recalling difficulties. Object naming assessed by the Boston test (Kaplan et al 1997) was not appropriate for age. He had difficulties in basic concepts relative to time. His mathematic skills were assessed to be particularly good.

The child was referred to medical speech pathologist at the age of 6 years because of speech production difficulties, and for diagnosis and further rehabilitation plan. He was then still found to have articulatory errors and dysphonology typical of developmental verbal dyspraxia. He had stable verbal and nonverbal lingual dysfunction resulting in dentoalveolar sound distortion. The /1/ sound was still palatalized in continuous speech, but no more in single words or in controlled speech production situations. Assimilations of alveolar sounds $/ \mathrm{s} /$ and $/ \mathrm{r} /$ occurred when produced in association with other consonants. The child had difficulties in protruding the tongue and bending it up to the upper lip. Movement of the tongue was not fully differentiated from the movement of the lower jaw. The tongue was structurally normal. No velopharyngeal or labial dysfunction was recognized. 
In neuropsychological testing by WPPS1-R (1995) and the items 3, 7, 15, 16, 30 of the NEPSY test (Korkman et al 1997) carried out at the age of 6 years, his nonverbal performance was in the average level for the age. Verbal performance was poorer compared to the nonverbal performance, and it was lower than the age average for his age. Auditive short term memory span was more limited than normal as tested by digits and sentences. Understanding of complicated sentences and instructed narrating of a heard story was age-appropriate, even though he scored a level of low normal.

The child did not present psychosocial problems in his relationship with friends. His ability to concentrate in doing tasks with an adult was considered good. There was no suspicion of ADHD. The child was physically healthy and had no allergies or ear infections. Both parents had probable dyslexia.

Individual speech therapy intervention and computer based augmentative rehabilitation devices were recommended. It was also found important to focus on phonological awareness to improve readiness for reading.

\section{Case 3}

A male child was born after normal pregnancy and delivery with normal physical health. According to health care recordings and information given by parents, he walked without support by the age of 10-11 months. The first words occurred before the age of 12 months, but the speech development was slow and remained limited.

He was examined by a local health care psychologist and assessed and rehabilitated by a speech therapist for 25 times. The following tests and assessment were carried out: auditive reasoning, understanding, and short term memory items of the ITPA-test (Kuusinen and Blåfield 1974), a Finnish articulation test (Remes 1975), a Finnish test for active vocabulary (Odell 1953), the Reynell language comprehension items (Kortesmaa et al 2001) and a Finnish sentence comprehension test (Korpilahti 1996), WPPSI-R (1995), and NEPSY (linguistic items) (Korkman et al 1997), Boehm test for basic concepts (Boehm 1993), drawing tasks, and play observation. Speech comprehension was below normal according to the Reynell test at the age of 4 years, but had become age average at the age of 5 years when re-tested. At that age, he had no problems in color naming or in basic concepts, but the speech was still severely unclear including instable sound substitutions, assimilations, and other errors typical of verbal dyspraxia. Narrating was somewhat limited.
The child was referred to special health care at the age of 5 years and 4 months for diagnosis and treatment design. Stable verbal and nonverbal lingual dysfunction was found. Tongue tip protruding and lifting on the upper lip was groping. The tongue tip was a little deformed in a little heart-like form due somewhat short but a thin and flexible frenulum of the tongue. The very mild tongue tie was not regarded to explain the phonological errors or stable lingual dysfunction resulting in dentoalveolar sound distortions, substitution, omission or assimilations. The /s/ and /1/ sounds were distorted. The /r/ sound was vowel like, assimilated or omitted depending on the phonetic context.

The boy was found cognitively normal. The performance was good average but the verbal skills were poor average. Visual perception was strongly above normal, albeit fine motor hand movements, such as using a pencil or binding the bands of the shoes were regarded clumsy .His parents regarded him skilled in different rough motor functions such as climbing and running, He had no allergies and only few otitis media. The hearing was tested by audiogram and found normal. There were no speedy walkers in close relatives.

Individual speech therapy recommended and assisting it with intraoral removable oral-plate treatment was considered. The therapy was focused on improvement of dentoalveolar articulation. The kindergarten personnel was involved in rehabilitation of the child's speech and language development, and an assisting nurse was introduced. The assessment of the abilities required for school attendance was scheduled.

\section{Case 4}

A physically healthy boy was born after normal pregnancy and delivery. He started to walk unassisted at the age of 8.5 months. His first words occurred at the age of 18 months and he formed sentences by the age of 2 years and 5 months. The speech was already from the beginning very unclear, and he had received speech therapy for three years from the age of 2 years. In the beginning his active vocabulary was below age level, but grew to be average for at the age of 4 years, when also the Reynell III test (Finnish version; Kortesmaa et al 2001) results indicated normal speech comprehension.

According to kindergarten reports, the boy was very active, lively, and daring. He was regarded to be skilled in rough motor functions. Although the child spoke a lot and had long sentences, his speech was still unintelligible and he suffered from it. He was referred to medical speech pathologist at the age of 5 years, when neuropsychological testing was also carried out. Both nonverbal performance and 
verbal performance was at the age-appropriate level, and no significant discrepancy was found between them. Auditive short-term memory was age-appropriate as measured with sentences. He had no results below the age-appropriate average in any items. Visual perception and visuomotor function were normal at good level. Phonological processing and speech comprehension were also normal at good level. He had several misarticulations and inconsistent sound substitutions, also in vowels. He presented with lingual dysfunction resulting in substitutions and distortions of $/ \mathrm{r} /$, /s/, and /1/ sounds and he was not able to produce low vowels. Velopharyngeal or labial dysfunction was not found. His had dyslexia. The child had not suffered from any recurrent middle ear infections or allergies.

ORAL plate therapy was recommended with individual speech therapeutic intervention.

\section{Preliminary data of $\mathbf{6 0}$ consecutive cases}

Table 1 shows the summary data of the distribution of the age at unassisted walking and speech data among 60 consecutive speech and/or language disordered children studied preliminarily. Of those 60 children $23(38 \%)$ began to walk unassisted at the age of 11 months or earlier (Group A), and 37 (62\%) walked at the age of 12 months or later (Group B). SLI (with or without symptoms of verbal dyspraxia) was diagnosed in a total of 49 children, out of which 12/49 (24\%) suffered from receptive/mixed type of SLI. A total of 21/49 (43\%) children with SLI belonged to Group A. More precisely, 18/37 (48\%) of children with expressive type of SLI and only 3/12 (25\%) of children with receptive or mixed type of SLI begun to walk unassisted at the age of 11 months or earlier (Group A).

The age of walking without support was not evenly distributed between the two diagnostic groups. Expressive SLI was significantly associated with earlier walking age according to Mann-Whitney $U$ test $(U=126.00, p=0.022)$.

Table I Distribution of the age at independent walking in 60 children with speech or language disorder

\begin{tabular}{llll}
\hline & Group A/n (\%) & Group B/n (\%) & Total /n \\
\hline $\begin{array}{llll}\text { Speech or language } \\
\text { disorder }\end{array}$ & $23(38)$ & $37(62)$ & 60 \\
SLI & $21(43)$ & $28(57)$ & 49 \\
Expressive & $18(48)$ & $19(52)$ & 37 \\
Receptive & $3(25)$ & $9(75)$ & 12 \\
\hline
\end{tabular}

Notes: Group A, unassisted walking at the age of II months or earlier; Group B, unassisted walking at the age of 12 months or later.

Abbreviations: SLI, specific speech-language disorder; n, number.
In the total group of 60 children, the ones with expressive speech production disorders (including children with mild ankyloglossia and impaired speech without diagnosed SLI) walked significantly earlier than the ones with speech comprehension problems (Mann-Whitney U test, $\mathrm{U}=195.5$, $\mathrm{p}=0.013)$.

Counting out the children who began walking at the age of 11 or 12 months, 10/16 (63\%) children were left, who had expressive speech problems and walked without support before the age of 11 months. Also 6/16 (37\%) children were left who had expressive speech impairment, and who walked at the age of 13 months or later. None of those children that had receptive or mixed SLI belonged to the earlier walking group. The difference was statistically significant (Fisher's exact test, $\mathrm{p}=0.035$ ).

The children with expressive SLI had significantly more often relatives with speedy walking than the children with mainly receptive SLI (Fisher's exact test, $\mathrm{p}=0.044$ ). The groups did not differ from each in respect to familial occurrence of speech/language or reading disabilities.

\section{Discussion}

Multidisciplinary speech evaluation and longitudinal follow ups were carried out in all the four cases described in this study. The clinical diagnostics can therefore be regarded as adequately performed. It appeared that the children demonstrated characteristics typical of APD, SSD, DVD/ DAS, or expressive SLI (DSM IV, ICD 10).

The milestones of gross motor development are reported in terms of starting to walk without support. Data of the age at which the first unassisted steps were made and when the occurrence of the first words and sentences occurred were obtained by the parents' reports and the carefully made baby clinic recordings. Parental information of developmental milestones must be taken with caution. There are no clear criteria to recognize the first steps, words or sentences. However, parents typically note those milestones that are often emotionally charged so that they write them into baby books that are common in Finnish families. Parents tend to remember the developmental milestones of walking very well, even when the child is 3-years-old, and still fairly well, when the child is 5-years-old. However, recall of first words is less exact (Majnemer and Rosenblatt 1994). In these children, parents' reports of developmental milestones were confirmed by health care registrations. Although the children were reported skilled in many rough motor functions, such as climbing, running, bicycling, and various sports, data were not collected because of the difficulties of obtaining reliable data. 
A behavioral pattern of unbalanced motor and speech development is typical to the present children and similar to those described earlier by Haapanen (2007). The children presented with a triad of speedy unsupported walking ability associated with expressive speech impairment including inconsistent error characteristics typical of developmental verbal dyspraxia, as well as stable misarticulations. The consistent speech sound production errors were found to result from lingual dysfunction, in terms of the inability to lift and broaden the tip of the tongue on the upper lip or alveolar ridge and the deficiency in the control of lateral borders of the tongue. The present misarticulations resemble those due to undifferentiated lingual gestures that were described by Gibbon (1999). One of the present children could not produce low back vowels. Misarticulations of dentoalveolars and low vowels probably indicate difficulty in lowering the body and back of the tongue. Typically consistent misarticulations occurred in the late developing alveolar, nonnasal continuous consonants $(/ \mathrm{s} /, / 1 /, / \mathrm{r} /)$. They were consistently distorted, but they also underwent inconsistent dysphonological processes such as omissions, substitutions, assimilations or reversals. No labial or velopharyngeal dysfunction occurred even though labials of velar stop consonants were inconsistently correctly produced/omitted/substituted or changed by other processes typical of verbal dyspraxia. In the case of two children, the neuropsychological discrepancy criteria that is used when diagnosing SLI (eg, DSM IV, ICD 10) was not fulfilled, which is not, however, necessary in diagnosing verbal dyspraxia (cf. Forrest 2003). It may not be possible to differentiate between DVD and SSD, that may occur with or without coexisting language disorder (Lewis et al 2006).

Consistent lingual dysfunction that occurred in the present children and in those described by Haapanen (2007) has not so far been reported as typical of verbal dyspraxia. However, the lingual dysfunction found in SPEEDY babies may be similar to tongue motor difficulties, of which Kent (1992) has stated that speech motor variability resulting in phonetic variability of speech sounds can be so great that it results in an apparent variability in phonology, ie, in dysphonology. Concomitant dysarthria was not diagnosed, even though not fully excluded. Murdoch and colleagues (1995) have found that children with DVD may have weaker lingual musculature and exhibit significantly reduced tongue strength endurance than the controls. This may indicate coexisting dysarthria in DVD children.

Even though the present children experienced with only a few consistent misarticulations, their speech disorder can be regarded as moderate or severe because of particularly inconsistent sound substitutions, omissions and assimilations. The $/ \mathrm{r} /, / \mathrm{s} /$, and $/ 1 /$ sounds are sounds that develop late and are often misarticulated in children even at the preschool age (Luotonen 1995). The Finnish / $r$ / sound is generally found very difficult to produce because of anterior tongue tip vibration necessary for normative / $\mathrm{r} /$. The persisting / $\mathrm{r}$ / sound disorders in Finnish children have been taken as a marker of verbal dyspraxia (Qvarnström et al 1993). The difference between the present SPEEDY babies and typically developing children is, however, their dysphonology which is rare in the common population (Tomblin et al 1997).

An interesting finding is that the present SPEEDY babies, as well as those described by Haapanen (2007) seem to be physically healthy. Recurrent middle ear infections and respiratory allergies are uncommon among them. However, the children are prone to social problems, because of unclear speech. They also can be taken as troublemakers because of their motor activity that results in demands for continuous attention to their physical safety, particularly in early infancy.

Since speedy rough motor development seems to be clustered in some children with idiopathic expressive speech impairment, particularly with speech characteristics typical of developmental verbal dyspraxia and consistent lingual dysfunction, it seems justifiable to consider those behavioral phenomena occurring as a syndrome. It is obvious that early walking does not explain the speech disorder, but there may be an inherited link between those developmental characteristics. Interestingly, according to our preliminary observations, children that start walking early independently seem to be fairly common among speech disordered children, particularly among those with expressive speech-language disorders. In the present preliminary series of 60 consecutive cases, none of the children who had receptive SLI walked before the age of 11 months. On the contrary, speedy motor development seems to be more often associated with delayed achievement of expressive speech considered normal by articulation or phonolgy. An interesting question arises: does biodiversity among human beings also appear in terms of bipolarity of the achievement of behavioral developmental milestones?

Speedy walking development also seems to be common in the family members of both SPEEDY babies and of those speech-language disordered children, who have started to walk at typical age. The children that start walking at typical age, but present with expressive SLI seem to have significantly more often relatives with speedy walking than the children with receptive SLI. This has not so far 
evoked any attention. Instead, much attention has been paid on familial co-occurrence of speech/language and reading/writing disorders (Stormswold 1998; Barry et al 2007), which also are common in SPEEDY babies, both in the present children and in those presented by Haapanen (2007). However, speech or reading and writing disorders do not seem to be significantly associated with either of the SLI subtypes, whether expressive or receptive. It seems that dyslexia may not be as seemingly associated with early independent walking as expressive speech disorders seem to be. It is obvious that the association between the timetable of independent walking and speech and learning development warrants further studies.

Albeit developmental disorders of motor functions have been studied much (Hill 1998; Webster et al 2006), hardly any attention is paid on atypically speedy motor development in association with speech-language disorders. The speechlanguage disordered population is very heterogeneous. An unclear phenotypic diagnostics obscures the study populations and slow down accumulation of knowledge of this population (SLI Consortium 2004). In order to gather phenotypic and genotypic information and to design recognition and rehabilitation strategies of individuals with communication disorders, it is important to try to search for particular developmental and behavioral characteristics that seem to cluster.

To delineate and sharpen the clinical picture of SPEEDY babies, it is worth further studies to eg, examine how common speedy unassisted walking is among speech-language disordered population, how do the behavioral characteristics vary in different ages, how variable is their cognitive profile, what are their fine motor functions like. Speedy rough motor and postural control development does not guarantee skilled fine motor functions, such as eg, eye-hand motor functions (Viholainen et al 2006).

It is noteworthy that the present children were fairly old, ie, 5- or 6-years-old, before they were referred to a medical specialist for further studies and arrangement of the financial recourses for their rehabilitation. This late referral was probably due to the suggested obviously good cognition. It is probable that their speech problems were thought to relapse by them selves. It is emphasized that early recognition of the problems SPEEDY babies is important, so that treatment strategies may be developed. So, attention should be paid on each baby starting to walk atypically early. Early intervention on speech problems and appreciation of early gross motor skills will aid in sustaining appropriate self confidence in these often lively and active children. SPEEDY babies require health care that recognizes and respects their motor skills and supports their needs for motor activities. They also require treatment for impaired speech. The parents may need advice and support with these children.

\section{Disclosure}

The authors report no conflicts of interest in this work.

\section{References}

Barry JG, Ysain I, Bishop DVM. 2007. Heritable risk factors associated with language impairments. Genes Brain Behav, 6:66-6.

Bishop DVM, Edmundson A. 1986. Is otitis media a major cause of specific developmental language disorders? Br J Disorders Commun, 21:321-38.

Bishop DVM, Edmundson A. 1987. Specific language impairment as a maturational lag: evidence from longitudinal data on language and motor development. Dev Med Child Neurol, 29:442-59.

Boehm AE. 1986. The Boehm test of basic concepts. USA: The psychological corporation. Heimo H. 1993. Boehmin peruskäsitetesti [Finnish version]. Helsinki: Psykologien kustannus OY.

Davis BL, Jakielski KJ, Marquardt TP. 1998. Developmental apraxia of speech: determiners of differential diagnosis. Clin Linguist Phon, 12:25-45.

Davis BL, Jacks A, Marquardt TP. 2005. Vowel patterns in developmental apraxia of spech: three longtiudinal case studies. Clin Linguist Phon, 19:249-74.

DSM-IV 1994. Diagnostic and statistical manual of mental disorders. 4th ed. Washington DC: AMA

Forrest K. 2003. Diagnostic criteria of developmental apraxia of speech used by clinical speech-language pathologists. Am J Speech Lang Pathol, 12:376-80.

Gibbon FE. 1999. Undifferentiated lingual gestures in children with articulation/phonological disorders. J Speech Lang Hear Res, 42:382-97.

Haapanen ML. 2007. Vauhtiveikot tulevat - uusi behavioraalinen oireyhtymä? SPEEDY babies are coming! A new behavioral syndrome? [abstract in English]. Finnish Med J, 39: 3531-4.

Hill EL. 1998. A dyspraxic deficit in specific language impairment and developmental coordination disorder? Evidence from hand and arm movements. Dev Med Child Neurol, 40:388-95.

ICD-10.1992. Geneve, WHO. Suomalainen laitos: ICD-10.1999 [Finnish version]. Turenki: Sosiaali- ja terveysalan tutkimus- ja kehittämiskeskus.

Jacks A, Marquardt TP, Davis BL. 2006. Consonant and syllable structure patterns in childhood apraxia of speech: developmental change in three children. J Comm Disord, 39:424-41

Kaplan E, Goodglass H, Weintraub S. 1983. Boston naming test. Baltimore: Waverly Inc. [Finnish version] Laine M, Koivuselkä-Sallinen P, Hänninen R, et al. 1997. Helsinki: Psykologien kustannus.

Kaplan BJ, Wilson DN, Dewey D, et al. 1998. DCD may not be a discrete disorder. Hum Mov Sci, 17:471-90

Kent RD. 1992. The biology of phonological development. In: Ferguson CA, Menn L, Stoel-Gammon C (eds). Phonological development: Models, research, implications. Timonium, MD: York Press, pp. 65-90.

Korkman M, Kirk U, Kemp SL. 1997. NEPSY - lasten neuropsykologinen tutkimus. Psykologien kustannus OY, Helsinki. [English version] Korkman M, Kirk U, Kemp S. 1998. NEPSY: A Developmental Neuropsychological Assessment. San Antonio, TX: Psychological Corporation.

Korpilahti P. 1996. Lausetesti: Test for the language comprehension of sentences. Helsinki: Helsinki University Press.

Kortesmaa M, Heimonen K, Merikoski H, et al. 2001. Finnish version of Reynell Developmental Language Scales III. Helsinki: Psykologien Kustannus OY. 
Kuusinen J, Blåfield L. 1974. Psykolingvististen kykyjen testi ITPA: testaajan opas. Jyväskylän yliopisto. Jyväskylä: Kasvatustieteiden tieteiden tutkimuslaitoksen julkaisuja, 234.

Lewis BA, Freebairn LA, Hansen AJ, et al. 2006. Dimensions of early speech sound disorders: A factor analytic study. J Commun Disord, 39:139-57.

Luotonen M. 1995. Early speech development, articulation and reading ability up to the age of 9. Folia Phoniatr Logop, 47:310-7.

Majnemer A, Rosenblatt B. 1994. Reliability of parental recall of developmental milestones. Pediatr Neurol, 10:304-8.

McGrath LM, Pennington BF, Willcut EG, et al. 2007. Gene x Environment interactions in speech sound disorder predict language and preliterary outcomes. Dev Psychopathol, 19:1047-72.

Murdoch BE, Attard MD, Ozanne AE, et al. 1995. Impaired tongue strength and endurance in developmental verbal dyspraxia: a physiologic analysis. Eur J Disord Commun, 30:51-64.

Nijland L, Maassen B, van der Meulen S. 2003. Evidence of motor programming deficits in children diagnosed with DAS. J Speech Hear Lang Res, 46:437-50.

Ptok M, Eysholdt U. 2005. The effects of recurrent otitis media with effusion on speech development [German]. HNO, 53:71-7.

Qvarnström MJ, Jaroma SM, Laine MT. 1993. Accuracy of articualtory movements of speech in a group of first-graders. Folia Phoniatr, 45:214-22.

Remes K. 1975. Artikulaatiotesti. Kuvakortisto puheenkehityksen ja äännevirheisyyden tutkimiseen ja tarkkailuun. Helsinki: Koulun erityispalvelu $\mathrm{Oy}$.

Rintala P, Pienimäki K. Ahonen T, et al. 1998. The effects of a psychomotor training programme on motor skill development in children with developmental language disorder. Hum Mov Sci, 17:721-37.

Robinson RJ. 1991. Causes abd associations of severe and persistent specific speech and language disorders in children. Dev Med Child Neurol, 33:943-62.

Rorschach H. 1948. Psychodiagnostik: Methodik und Erbegnisse eines wahrnehmunsdiagnostichen Experiments: mit den zuhörigen Tests bestehend aus zehn teils mehrfarbigenTafeln. Verlag Hans Huber. Bern.
Sanger TD, Chen D, Delgado MR, et al. 2006. The Task Force on childhood motor disorders: Definition and classification of negative motor signs. Pediatrics, 118:2159-67.

SLI Consortium. 2004. Highly significant linkage to the SLI1 locus in an expanded sample of indivuals affected by specific language impairment. Am J Hum Genet, 74:1225-38.

Shriberg LD, Lewis BA, Tomblin JB, et al. 2005. Toward diagnostic phenotype markers for genetically transmitted speech delay. $J$ Speech Lang Hear Res, 48:834-52.

Stormswold K. 1998. Genetics of spoken language disorders. Hum Biol, 70:293-320.

Webster RI, Majnemer A, Platt RW, et al. 2005. Motor functioning in school age children with a preschool diagnosis of specific language impairment (SLI). J Pediatr, 146:80-5.

Tallal P, Ross R, Curtiss S. 1989. Unexpected sex-ratios in families of language impairment. J Speech Hear Disord, 54:167-73.

Tomblin JB, Records NL, Buckwalter P, et al. 1997. Prevalence of specific language impairment in kindergarten children. $J$ Speech Lang Hear Res, 40:1245-60.

Webster RI, Erdos C, Evans K, et al. 2006. The clinical spectrum of developmental language impairment in school-aged children: language, cognitive, and motor findings. $J$ Pediatr, 118:1541-9.

Wechsler D. 1990. Wechsler preschool and primary scale of intelligence revised (WPPSI-R). New York: The Psychological Corporation. (Finnish version) 1995. Helsinki: Psykologien kustannus OY.

Weschler D. 1974. Wechsler Intelligence scale for children - III (Wisc-III). UK: The Psychological Corporation. [Finnish version]. 1999. Helsinki: Psykologien Kustannus OY.

[WHO] World Health Organization: Multicentre Growth Reference Study Group. 2006. WHO Motor development study: windows of achievement for six gross motor development milestones. Acta Paediatr Suppl, 450:86-95.

Viholainen H, Ahonen T, Cantell M, et al. 2006. The early motor milestones in infancy and later skills in toddlers: a structural equation model of motor development. Phys Occup Ther Pediatr, 26:91-113. 
